\title{
Histochemical and Cytochemical Investigations of Phenols in Roots of Banana Infected by the Burrowing Nematode Radopholus similis
}

\author{
C. Valette, C. Andary, J. P. Geiger, J. L. Sarah, and M. Nicole
}

First and fourth authors: Laboratoire de Nématologie, CIRAD, BP 5035, 34032 Montpellier, France; second author: Laboratoire de Botanique et Phytochimie, Faculté de Pharmacie, Université de Montpellier 1, 15 Avenue G. Flahaut, 34060 Montpellier, France; and third and fifth authors: Laboratoire de Phytopathologie, ORSTOM, BP 5045, 34032 Montpellier, France. Accepted for publication 30 July 1998.

\begin{abstract}
Valette, C., Andary, C., Geiger, J. P., Sarah, J. L., and Nicole, M. 1998. Histochemical and cytochemical investigations of phenols in roots of banana infected by the burrowing nematode Radopholus similis. Phytopathology 88:1141-1148.

The burrowing nematode Radopholus similis is one of the most damaging pathogens on banana plantations. The role of phenolics in plant defense responses to the nematode was histochemically and ultrastructurally investigated in susceptible and partially resistant cultivars. Histochemical observations of healthy roots revealed that high levels of lignin, flavonoids, dopamine, cafeic esters, and ferulic acids were associated with a very low rate of nematode root penetration in the resistant cultivar. The

presence of lignified and suberized layers in endodermal cells contributed to limit invasion of the vascular bundle by the pathogen. After infection, flavonoids were seen to accumulate early in walls of cells close to the nematode-migrating channel in both cultivars and in all tissues of the infected resistant roots including the vascular tissues. The labeling pattern obtained with the gold-complexed laccase and with anti-pectin monoclonal antibodies showed that phenolics were distributed in a loosened pectin-rich material surrounding the nematode. This study provides indications that constitutive phenolics in banana roots are associated with the limitation of host penetration and colonization by $R$. similis. Accumulation of flavonoids in response to infection was detected in the vascular tissues of susceptible plants and in all root tissues in the partially resistant plants.
\end{abstract}

Nematodes are considered one of the main threats among pests that significantly reduce yield in banana crops. The endoparasitic migratory parasite Radopholus similis is the most widely distributed nematode in banana plantations $(14,33)$. Important variations in levels of resistance to $R$. similis have been reported within a wide range of banana cultivars $(11,12,29)$. Field and greenhouse trials have revealed that the partially resistant cultivar Yangambi Km 5 (subgroup Ibota, AAA) is much less infected by $R$. similis compared with the susceptible cultivar Poyo (subgroup Cavendish, AAA). After inoculation, the population of $R$. similis in banana roots was fourfold higher in 'Poyo' than in 'Yangambi Km 5' (10,34). In fields, 'Yangambi Km 5' generally showed a very high degree of resistance with nearly no development of $R$. similis populations (31).

Histological investigations of infected tissues have shown that $R$. similis is the primary pathogen of banana root rot. Although observed in the vascular stele (38), this nematode is mainly located in the cortical parenchyma, where it is associated with host cell damage, mainly characterized by retraction of the plasma membrane and wall degradation $(5,39)$. Several responses of banana roots to $R$. similis invasion have been reported including hyperplasia of cells close to the endodermis and occlusion of sieve tubes by active deposition of callose (38). The observation that electron-dense compounds accumulated in cortical and vascular parenchyma cells has led to suggestions that phenolics could be involved in the plant defense responses to the nematode. Mace (21) previously established that specialized cells in healthy banana roots contained high concentrations of phenols, identified as 3-hydroxytyramine (dopamine). Although phenolics in banana roots are known to be formed in response to infection by various pathogens $(2,3,21,22)$ including

Corresponding author: M. Nicole; E-mail address: nicole@mpl.orstom.fr

Publication no. P-1998-0918-01R

(C) 1998 The American Phytopathological Society nematodes (11), little information is available on the nature of these compounds and their potential role in defense against $R$. similis.

The purpose of the current study was to histochemically and cytochemically investigate the production of phenolic compounds in healthy and $R$. similis-infected banana roots of the partially resistant cultivar Yangambi Km 5 and the susceptible cultivar Poyo. We provide evidence that there are striking differences in phenolic contents in healthy roots of the two banana cultivars, which could contribute to the passive defense of the resistant cultivar. After controlled infection, nematode ingress was associated with marked metabolic changes in phenolics, mainly characterized by local production of flavonoids along the pathogen pathway and a general accumulation in tissues of the partially resistant host.

\section{MATERIALS AND METHODS}

Plants and nematodes. The susceptible ('Poyo'; Musa, AAA) and partially resistant ('Yangambi Km 5'; Musa, AAA) banana plants, as well as the nematode population used in this study, have been described previously (34). Inoculum was a mixture of adult and juvenile nematodes. The concentration of nematodes in the suspension was adjusted for inoculation (1,600 nematodes per ml) (37). The inoculum was directly applied to roots of 1-month-old plants, $1 \mathrm{~cm}$ from the tips. Four roots per plant were inoculated, each with 800 nematodes in $0.5 \mathrm{ml}$ of water. For microscopic observations, roots were sampled $24,48,72$, and $96 \mathrm{~h}$ after inoculation.

Histochemistry. Sections ( 40 to $60 \mu \mathrm{m}$ thick) were made on fresh root samples from healthy and infected roots with a freezing-stage microtome (Leica, Paris). Within 2 to $5 \mathrm{~min}$, sections were treated with histochemical reagents for the localization of phenolics. They were then mounted in the reagents or in glycerin/water $(15: 85$, $\mathrm{vol} / \mathrm{vol}$ ) and examined by light or epifluorescence microscopy (Optiphot; Nikon Corp., Tokyo) using one of the two following filter sets: an UV filter set with a $365-\mathrm{nm}$ excitation and a 400-nm barrier filter or a blue filter set with a 420-nm excitation and a 515- to 
560-nm barrier filter. Autofluorescence was also monitored by epifluorescence microscopy.

Lignin was visualized with Mirande's reagent (8); sections were immersed in sodium hypochlorite (48\% active chlorine) for $5 \mathrm{~min}$, rinsed with distilled water, immersed for $5 \mathrm{~min}$ in a solution of carmine (number 40; Prolabo, Paris) and iodine green (Prolabo), rinsed with distilled water, and observed with the light microscope. Lignin compounds stained green. Sections immersed in $10 \%$ phloroglucinol in absolute ethanol followed by $\mathrm{HCl}$ displayed red-stained lignins.

Suberin was examined using a Sudan IV (Sigma Chemical Co., St. Louis) alcohol-saturated solution as previously described (16). Suberin appeared brownish after 15 min of staining.

Condensed tannins (i.e., pro-anthocyanidins) were stained by immersing sections for 2 to $5 \mathrm{~min}$ in DMCA (0.5 M sulfuric acid in butanol plus $0.1 \%$ 4-dimethylaminocinnamaldehyde) (Prolabo) and examined with the light microscope. Tannins stained dark blue or blue-green. Catechins (monomers) and condensed tannins (oligo-polymers) were detected with vanillin- $\mathrm{HCl}$ after sections were immersed for $5 \mathrm{~min}$ in a $10 \%$ (wt/vol) vanillin solution (Carlo Erba, Rome) in a volume of absolute ethanol mixed with a volume of concentrated $\mathrm{HCl}$; mounted in this reagent, these compounds stained red.

Flavonoid compounds were detected with Neu's reagent (26). Sections were immersed for 2 to $5 \mathrm{~min}$ in $1 \%$ 2-amino-ethyldiphenylborinate (Fluka, Buchs, Switzerland) in absolute methanol, mounted in glycerin-water, and examined by epifluorescence microscopy. Flavonoids stained yellow-orange under UV light and lemon yellow when observed with blue light. The results were confirmed with the lead acetate reagent (20\% aqueous solution of basic lead acetate; Prolabo) (C. Andary, unpublished data). After treatment of sections with Neu's reagent, caffeic esters stained blue-white and ferulic acid stained blue when UV-illuminated $(6,25)$.

Characterization of dopamine (whitish blue under UV light) was performed on sections immersed in a solution of lactic and glyoxilic acids and heated at $100^{\circ} \mathrm{C}$ for $1 \mathrm{~min}$ (C. Andary, C. Valette, J. L. Sarah, and M. Nicole, unpublished data). Sections were then observed with the epifluorescence microscope.

Ultrastructural observations. Samples were treated as previously described (38) for electron microscope observations. Briefly, samples from infected and healthy roots were fixed for $2 \mathrm{~h}$ in $2.5 \%$ buffered glutaraldehyde. After several washes with cacodylate buffer, the specimens were postfixed for $1 \mathrm{~h}$ in $1 \%$ osmium tetroxide $\left(\mathrm{OsO}_{4}\right)(\mathrm{wt} / \mathrm{vol})$, dehydrated through an ethanol series and propylene oxide, and embedded in Epon. Ultrathin sections were stained with uranyl acetate and lead citrate and then examined with a JEOL 100EX electron microscope (JEOL, Ltd., Tokyo) operating at $80 \mathrm{kV}$.

Immunolocalization of pectin epitopes. Postfixed tissues with $\mathrm{OsO}_{4}$ were used for pectin immunolabeling with the JIM 5 monoclonal antibody (18). Osmium tetroxide both weakly altered poly- saccharides epitopes and allowed a good ultrastructural preservation of tissues. Sections were first floated on a drop of phosphatebuffered saline (PBS)-bovine serum albumin (BSA) (1\%)-Tween $(0.05 \%)$, and then incubated for $2 \mathrm{~h}$ at $37^{\circ} \mathrm{C}$ on a drop containing the primary antibody. After washing in PBS, sections were floated for $30 \mathrm{~min}$ at $37^{\circ} \mathrm{C}$ on a drop of gold-labeled goat anti-rat antibodies (GAR-10nm; BioCell Research Laboratories, Cardiff, United Kingdom) diluted 1:20 in Tris/HCl-BSA (1\%)-Tween $20(0.05 \%)$. Controls used for immunolabeling of healthy and infected roots were performed as previously described (7).

Cytochemical localization of phenol-like compounds. This was performed with a purified laccase (EC 1.10.3.2) conjugated to colloidal gold at $\mathrm{pH} 5.02$ (4). Labeling of sections was performed for $30 \mathrm{~min}$ at $25^{\circ} \mathrm{C}$ on a drop of the gold probe in $0.1 \mathrm{M}$ PBS and $0.01 \%$ PEG ( $\mathrm{pH} 6.0$ ). Specificity of labeling was assessed by incubating sections with the gold-complexed laccase previously incubated with $1 \%$ guaiacol, $0.25 \mathrm{M}$ ferulic acid, or $0.15 \mathrm{M}$ chlorogenic acid.

\section{RESULTS}

Typical reddish-brown cortical lesions developed on susceptible roots by 4 days after inoculation. Lesions were less visible on roots of the resistant cultivar.

Histochemistry. Histochemical detection of phenolics on sections from healthy and infected roots were compared (Tables 1 and 2).

Healthy plants. After treatment of sections made in differentiated root portions with Neu's reagent, walls of epidermal, parenchymal, and vascular cells of the resistant cultivar emitted yellow and orange-red fluorescence upon excitation at $365 \mathrm{~nm}$, while they displayed a lemon yellow fluorescence after excitation at $420 \mathrm{~nm}$, suggesting the presence of flavonoids. Ferulic acid, identified by a blue fluorescence under UV light and no fluorescence under blue light, was seen in walls of cortical cells. Vessel cell walls of the resistant cultivar also showed a blue-white fluorescence when observed at $365 \mathrm{~nm}$ and a strong yellow fluorescence under blue light, suggesting the occurrence of caffeic esters. No significant staining of root sections from the susceptible cultivar was seen after treatment with Neu's reagent.

Observations of sections stained with Mirande's reagent or phloroglucinol- $\mathrm{HCl}$ revealed that young parts of roots above the meristematic zone and parenchyma cells of both cultivars did not show any apparent lignin deposits (data not shown). Positive staining for lignin with Mirande's reagent and suberin with Sudan dye was observed in differentiated areas of the stele in the two cultivars, but to a lesser extent in the susceptible cultivar. Staining for suberin was also observed in endodermis cell walls in resistant roots.

Staining with DMCA for condensed tannins was negative for the two cultivars. Detection of dopamine revealed that this phe-

TABLE 1 . Histochemistry of phenol compounds in healthy banana roots

\begin{tabular}{|c|c|c|c|c|c|c|c|c|c|c|c|}
\hline \multirow[b]{2}{*}{ Reagents } & \multirow[b]{2}{*}{ Light } & \multirow[b]{2}{*}{ Phenols } & \multirow[b]{2}{*}{ Cultivars $^{\mathrm{a}}$} & \multicolumn{4}{|c|}{ Magnitude of staining over time (h) ${ }^{\mathrm{b}}$} & \multicolumn{4}{|c|}{ Sites of reaction over time $(\mathrm{h})^{\mathrm{c}}$} \\
\hline & & & & 24 & 48 & 72 & 96 & 24 & 48 & 72 & 96 \\
\hline \multirow[t]{2}{*}{ Autofluorescence } & UV & Flavonoids & $\mathrm{S}$ & - & - & - & - & - & - & - & - \\
\hline & & & $\mathrm{R}$ & - & - & - & - & - & - & - & - \\
\hline \multirow{3}{*}{ Neu } & & & $\mathrm{R}$ & + Blue-white & + Blue-white & + Blue-white & + Blue-white & $\mathrm{CE}$ & $\mathrm{CE}$ & $\mathrm{CE}$ & $\mathrm{CE}$ \\
\hline & & Flavonoids & $\mathrm{S}$ & - & - & - & - & - & - & - & - \\
\hline & & & $\mathrm{R}$ & + Yellow & + Yellow & + Yellow & + Yellow & $\mathrm{CPE}$ & CPE & $\mathrm{CPE}$ & CPE \\
\hline \multirow[t]{2}{*}{ Mirande } & Visible & Lignin & $\mathrm{S}$ & \pm Green & \pm Green & \pm Green & \pm Green & $\mathrm{C}$ & $\mathrm{C}$ & $\mathrm{C}$ & $\mathrm{C}$ \\
\hline & & & $\mathrm{R}$ & ++ Green & ++ Green & ++ Green & ++ Green & $\mathrm{C}$ & $\mathrm{C}$ & $\mathrm{C}$ & $\mathrm{C}$ \\
\hline \multirow[t]{2}{*}{ Dopamine } & UV & Dopamine & $\mathrm{S}$ & + Blue-white & + Blue-white & + Blue-white & + Blue-white & $\mathrm{C}$ & $\mathrm{C}$ & $\mathrm{C}$ & $\mathrm{C}$ \\
\hline & & & $\mathrm{R}$ & ++ Blue-white & ++ Blue-white & ++ Blue-white & ++ Blue-white & $\mathrm{CE}$ & $\mathrm{CE}$ & $\mathrm{CE}$ & $\mathrm{CE}$ \\
\hline
\end{tabular}

${ }^{a} \mathrm{R}=$ 'Yangambi Km 5', resistant; and $\mathrm{S}=$ 'Poyo', susceptible.

$\mathrm{b}_{-}=$No reaction, $\pm=$weak reaction, $+=$moderate reaction, and $++=$strong reaction.

${ }^{\mathrm{c}} \mathrm{C}=$ vascular bundle, $\mathrm{E}=$ epidermis, and $\mathrm{P}=$ parenchyma cells. 
nolamine compound occurred abundantly in vascular cells and root epidermis of the resistant roots; in the susceptible plants, few vascular cells seemed to contain dopamine (Table 1).

Infected plants. When sections from infected roots of both cultivars were observed under UV light $24 \mathrm{~h}$ after inoculation, a yellow autofluorescence indicating the presence of flavonoids was observed in cells of the stele (Table 2). Two days after inoculation, this autofluorescence also occurred in the cortical parenchyma of both cultivars, but to a lesser extent in the susceptible cultivar.

The presence of flavonoids was confirmed by treatment of sections with Neu's reagent, which revealed a strong yellow-orange fluorescence in vascular cells with excitation at $365 \mathrm{~nm}$ and a lemon yellow fluorescence after excitation at $420 \mathrm{~nm}$ in the susceptible roots. Forty-eight and seventy-two h after inoculation, vascular cells of both cultivars were impregnated by flavonoids that fluoresced yellow-orange under UV light (365 nm) (Fig. 1A and C, susceptible and resistant, respectively) and lemon yellow under blue light $(420 \mathrm{~nm})$ (Fig. 1B and D, susceptible and resistant, respectively). A yellow fluorescence was also associated with the nematode. Cells bordering channels that resulted from nematode ingress within susceptible and resistant roots showed walls with a orangered fluorescence, indicating the presence of flavanones (Fig. 1E and F, large arrows). Four days after inoculation, this fluorescence was detected in all tissues of the resistant roots including cortical cells (Fig. 2A and B), but not in the susceptible roots, where fluorescence was found in the vascular tissues only (Fig. 2C and D).

The blue fluorescence that was seen under UV illumination $(365 \mathrm{~nm})$ in sections treated with Neu's reagent (Fig. 1A, C, and E) indicated that caffeic esters occurred in the infected roots of both cultivars, but no significant difference in staining was observed between both cultivars (data not shown).

Treatment of sections with basic lead acetate revealed that the vacuole of vascular parenchyma cells from the susceptible cultivar accumulated flavonoids (Fig. $1 \mathrm{G}$ and $\mathrm{H}$ ) earlier (from $24 \mathrm{~h}$ ) than cells of the resistant cultivar ( $96 \mathrm{~h}$ ) (Table 2). Flavonoids appeared pale yellow under UV light (365 nm) (Fig. 1G) and lemon yellow after excitation at $420 \mathrm{~nm}$ (Fig. 1H).

Staining for dopamine revealed that the intensity of the yellow fluorescence after blue illumination of sections was considerably lower in both infected cultivars as compared with healthy plants (Table 2). In susceptible roots, dopamine was not detected until $72 \mathrm{~h}$ after inoculation, while in the resistant roots, no apparent variations in staining intensity were detected according to the time course of infection.

No significant difference between the two cultivars in the content of lignin, suberin, ferulic acid, catechins, and tannins was recorded in sections from infected roots.

Ultrastructural features of root colonization by the nematode. After penetration in root tips, the parasite moved upwards mainly within the cortical tissues of both cultivars, but seldom in the vascular stele in the susceptible plants and never in the resis- tant plant. Adults were more abundant in the susceptible roots than in resistant roots $(12,38)$. Damage to the invaded host cells during colonization consisted of cell wall breakdown and cytoplasm digestion with loss of membrane integrity (38). Migration of nematodes in intercellular areas was associated with the presence of a highly electron-dense loosened fibrillar material (Fig. 3A) that was closely associated with the middle lamella.

Cytochemical localization of phenolics using a laccase-gold complex. A fungal laccase conjugated to colloidal gold was used to localize phenolic-like molecules associated with nematode ingress within the infected tissues. Labeling was detected over the loosened fibrillar material that surrounded the pathogen in resistant (Fig. 3B) and susceptible roots. With the exception of cell walls close to the fibrillar material, no gold particles were seen over other host cell structures and the nematode. In noninfected plants, labeling was absent. Incubation of the enzyme-gold probe with ferulic acid or chlorogenic acid prior to section treatment resulted in a very low labeling (Fig. 3C).

Immunocytochemical localization of pectin epitopes using the JIM 5 monoclonal antibody. After treatment of sections from infected root samples of both cultivars with the JIM 5 anti-pectin monoclonal antibody, gold particles were evenly distributed over the middle lamella of cortical cells (Fig. 3D). The fibrillar material that surrounded the pathogen also showed gold particles (Fig. 3E). On sections from healthy plants, labeling occurred over the middle lamellae and weakly over the primary walls of parenchyma cells (data not shown). No labeling was detected in the following control experiments performed on sections from healthy and infected roots: (i) incubation with the antiserum previously adsorbed with polygalacturonic acid, (ii) incubation with preimmune mouse serum instead of the primary antiserum, and (iii) omission of the primary antibody incubation step.

\section{DISCUSSION}

Over the past decade, considerable attention has been given to plant resistance to nematodes (35), with particular emphasis on resistance and defense genes of plants challenged by root-knot and cyst nematodes $(15,20,28)$. Comparatively, molecular and cellular events in plants following infection by burrowing nematodes have been poorly investigated. Among molecules that actively contribute to plant defense against pathogen invasion, phenolics have been convincingly shown to play a key role in limiting microbe extension in host tissues (27). Their characteristic reactions with histochemical reagents allow direct observation in planta (1). Histochemistry associated with molecular cytology can contribute to accurate observations of sites where defense molecules accumulate in plant cells.

In the current study, histochemical observations of sections from healthy banana roots showed striking differences in the phenolic contents between the susceptible 'Poyo' and the partially resistant

TABLE 2. Histochemistry of phenol compounds in infected banana roots observed under UV light

\begin{tabular}{|c|c|c|c|c|c|c|c|c|c|c|}
\hline \multirow[b]{2}{*}{ Reagents } & \multirow[b]{2}{*}{ Phenols } & \multirow[b]{2}{*}{ Cultivars $^{\mathrm{a}}$} & \multicolumn{4}{|c|}{ Magnitude of staining over time $(\mathrm{h})^{\mathrm{b}}$} & \multicolumn{4}{|c|}{$\begin{array}{l}\text { Sites of reaction } \\
\text { over time }(\mathrm{h})^{\mathrm{c}}\end{array}$} \\
\hline & & & 24 & 48 & 72 & 96 & 24 & 48 & 72 & 96 \\
\hline Autofluorescence & Flavonoids & $S$ & \pm Yellow & \pm Yellow, + orange-red & \pm Yellow, + orange-red & \pm Yellow, + orange-red & $\mathrm{C}$ & $\mathrm{PC}$ & $\mathrm{PC}$ & $\mathrm{PC}$ \\
\hline Neu & Flavonoids & S & \pm Yellow-orange & + Yellow-orange & + Yellow-orange & + Yellow-orange & V & $\mathrm{V}$ & $\mathrm{C}$ & $\mathrm{C}$ \\
\hline & & $\mathrm{R}$ & + Yellow-orange & + Yellow-orange & + Yellow-orange & ++ Yellow-orange & $\mathrm{C}$ & $\mathrm{C}$ & $\mathrm{C}$ & CPE \\
\hline Lead acetate & Flavonoids & $\mathrm{S}$ & + Yellow $^{\mathrm{d}}$ & + Yellow $^{\mathrm{d}}$ & + Yellow $^{\mathrm{d}}$ & + Yellow $^{\mathrm{d}}$ & $\mathrm{C}$ & $\mathrm{C}$ & $\mathrm{C}$ & $\mathrm{C}$ \\
\hline
\end{tabular}

a $\mathrm{R}=$ 'Yangambi $\mathrm{Km}$ 5', resistant; and $\mathrm{S}=$ 'Poyo', susceptible.

$\mathrm{b}_{-}=$No reaction, $\pm=$weak reaction, $+=$moderate reaction, and $++=$strong reaction.

${ }^{\mathrm{c}} \mathrm{C}=$ vascular bundle, $\mathrm{E}=$ epidermis, $\mathrm{P}=$ parenchyma cells, and $\mathrm{V}=$ vessels.

${ }^{d}$ Staining of the cytoplasm of medullar and parenchyma cells. 

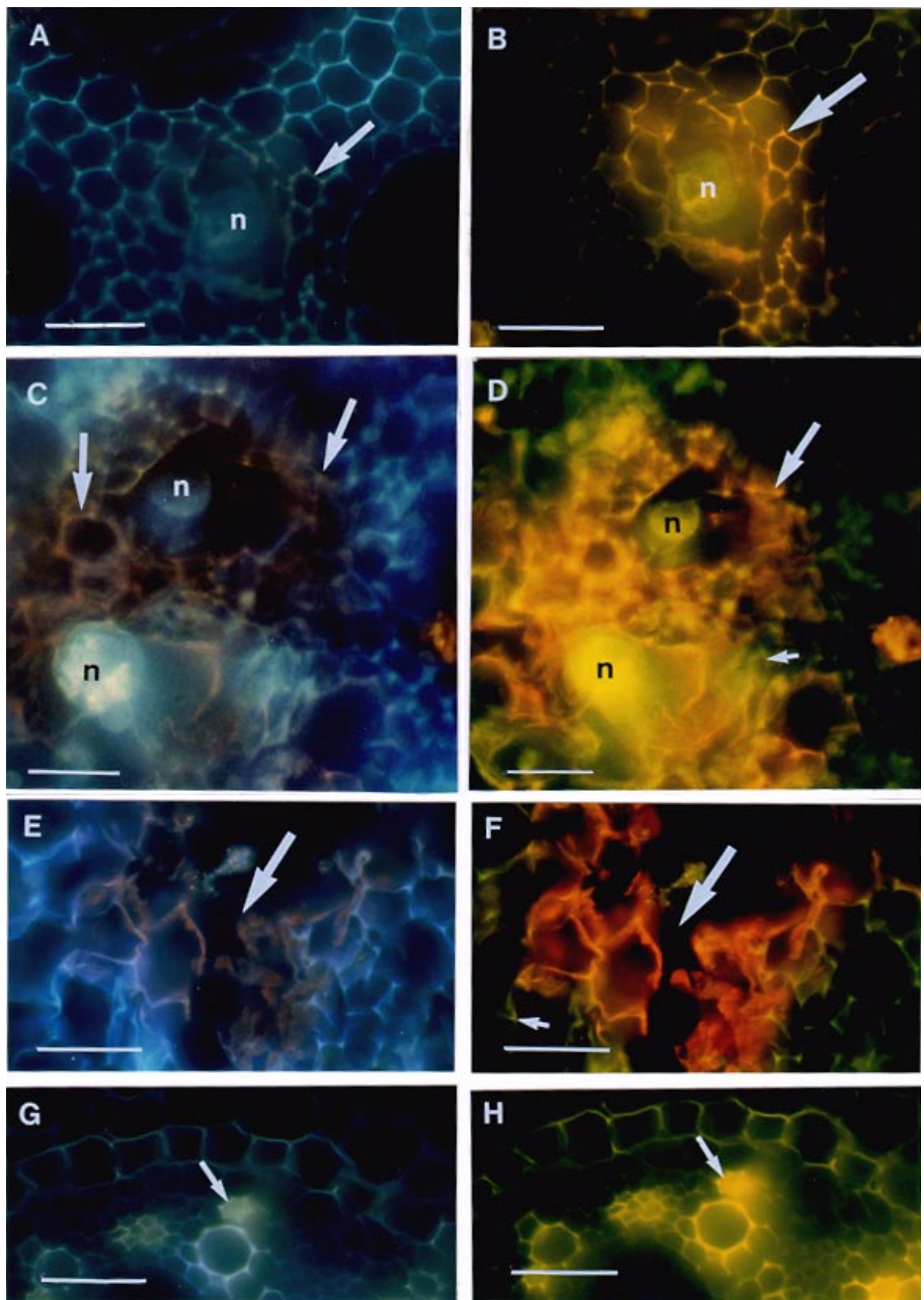

Fig. 1. Histochemical characterization of flavonoids in banana roots infected with Radopholus similis 72 h following inoculation. A, B, E, F, G, and H, susceptible plants; C and D, resistant plants. A to F, Thick sections ( 40 to $60 \mu \mathrm{m})$ treated with Neu's reagent. With epifluorescence observation under UV light, (365 nm) flavonoids stained A and C, yellow-orange (arrows) or E, orange (arrow). With epifluorescence observation under blue light (420 nm), flavonoids stained $\mathbf{B}$ and $\mathbf{D}$, lemon yellow; $\mathbf{B}$ and $\mathbf{D}$, orange; or $\mathbf{F}$, orange-red. Walls of infected parenchyma cells located close to the nematode (n) display a $\mathbf{A}$ and $\mathbf{C}$, yellow-orange (arrows); $\mathbf{B}$, orange (arrow); or $\mathbf{D}$, lemon yellow fluorescence (small arrow). B and D, The nematode (n) shows a yellow fluorescence. Fluorescence in roots of resistant plants is stronger that in susceptible plants. Walls of altered cells close to the nematode pathway (arrow) stained $\mathbf{E}$, orange under UV light or $\mathbf{F}$, orange-red under blue light. Bars $=10 \mu \mathrm{m}$. F, The yellow light (small arrow) indicates the presence of caffeic esters. $\mathbf{G}$ and $\mathbf{H}$, Thick sections treated with basic lead acetate. The vacuoles of parenchyma cells in the infected xylem display a $\mathbf{G}$, yellow pale (epifluorescence observation under UV light, $365 \mathrm{~nm}$ ) or $\mathbf{H}$, strong lemon yellow fluorescence (arrows; epifluorescence observation with blue light, $420 \mathrm{~nm})$. Bars $=5 \mu \mathrm{m}$.

\section{PHYTOPATHOLOGY}


'Yangambi Km 5'. The use of Neu's reagent indicated the presence of flavonoids and caffeic esters in parenchyma and vascular cells and of ferulic acid in walls of parenchyma cells in the resistant cultivar, while they were not detected in susceptible roots. Similarly, dopamine occurred abundantly in the resistant roots. The positive reaction obtained with Mirande's reagent and phloroglucinol- $\mathrm{HCl}$ revealed a high degree of lignification in the stele and the endodermis in the differentiated portions of the resistant roots as compared with the susceptible roots. By contrast, tips of roots of both cultivars were slightly lignified. In addition, only the endodermis cells of the resistant cultivar displayed a thick suberized layer that was not observed in the cells of the susceptible cultivar. These striking constitutive differences may explain why 'Yangambi $\mathrm{Km} 5$ ' resists $R$. similis infection, as already emphasized by Fogain and Gowen $(11,12)$.

Plant resistance to nematodes has been defined as the ability to restrict or prevent pathogen reproduction $(17,37)$. In a previous study (38), it has been reported that the number of nematodes and eggs from $R$. similis recovered from banana roots 2 days after inoculation was, on average, four times higher in the susceptible than for the resistant cultivar $(11,12)$, while none were observed 1 day after inoculation in resistant plants. These authors also indicated that this nematode was found in cortical parenchyma cells of both cultivars, but in the vascular stele of the susceptible variety only.
From our data, we conclude that in resistant banana (i) phenols including flavonoids, caffeic esters, and dopamine may limit root penetration by the nematode, and (ii) the high level of vascular lignification and suberization of endodermal cells restricts xylem invasion by, and prevents multiplication of, the pathogen in the vascular tissues.

In addition to the constitutive yellow-fluorescing flavonoids in the resistant cultivar, other compounds that stained orange-red with Neu's reagent and identified as flavanones (C. Andary, unpublished data) locally accumulated $48 \mathrm{~h}$ after inoculation in host cell walls close to the nematode-migrating channel in both cultivars. The staining by the lead acetate reagent indicated a vacuole localization of flavonoids in cells of the vascular parenchyma. Cytochemical localization of phenolic-like compounds by the laccasegold probe, which has been demonstrated to be a valuable probe to identify phenol substances in plant tissues $(4,19)$, accurately showed that some of them were found in the pectin-containing fibrillar material surrounding the nematode. The apparent loosening of this pectin-like structure may originate from modification in the middle lamella by nematodes as judged by alterations in ultrastructural patterns in this pathosystem (38). Although R. similis in banana roots displayed a blue or yellow fluorescence after staining with Neu's reagent, gold particles were not detected over the nematode after the use of the enzyme-gold complex, suggesting that this
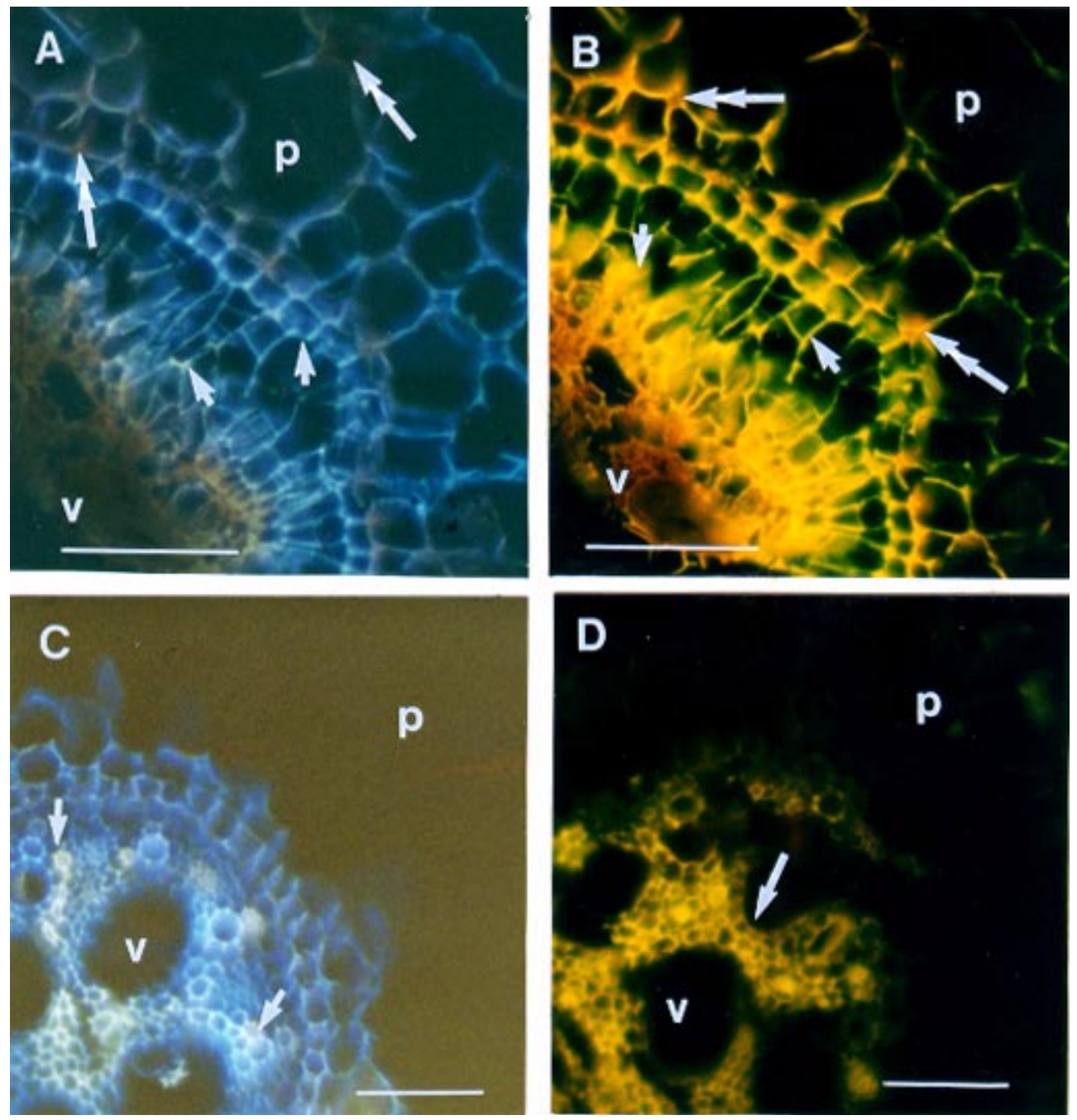

Fig. 2. Histochemical characterization of flavonoids in banana roots infected with Radopholus similis $96 \mathrm{~h}$ following inoculation. Sections were treated with Neu's reagent. In resistant plants, cells of both the cortical parenchyma (p) and the vascular stele (v) display fluorescence; A, under UV observation $(365 \mathrm{~nm})$ flavonoids appear yellow (arrows) or orange (double arrows); B, while they show a lemon yellow (arrows) or orange (double arrows) fluorescence when observed under blue light $(420 \mathrm{~nm}$ ). Bars $=10 \mu \mathrm{m}$. C and D, In susceptible plants, fluorescence is seen in the vascular stele (v), but is absent or weak in cortical cells. Flavonoids stained C, yellow under UV illumination (arrows; $365 \mathrm{~nm}$ ) and $\mathbf{D}$, lemon yellow when observed with blue light (arrows; $420 \mathrm{~nm}$ ). Bars $=40 \mu \mathrm{m}$. 

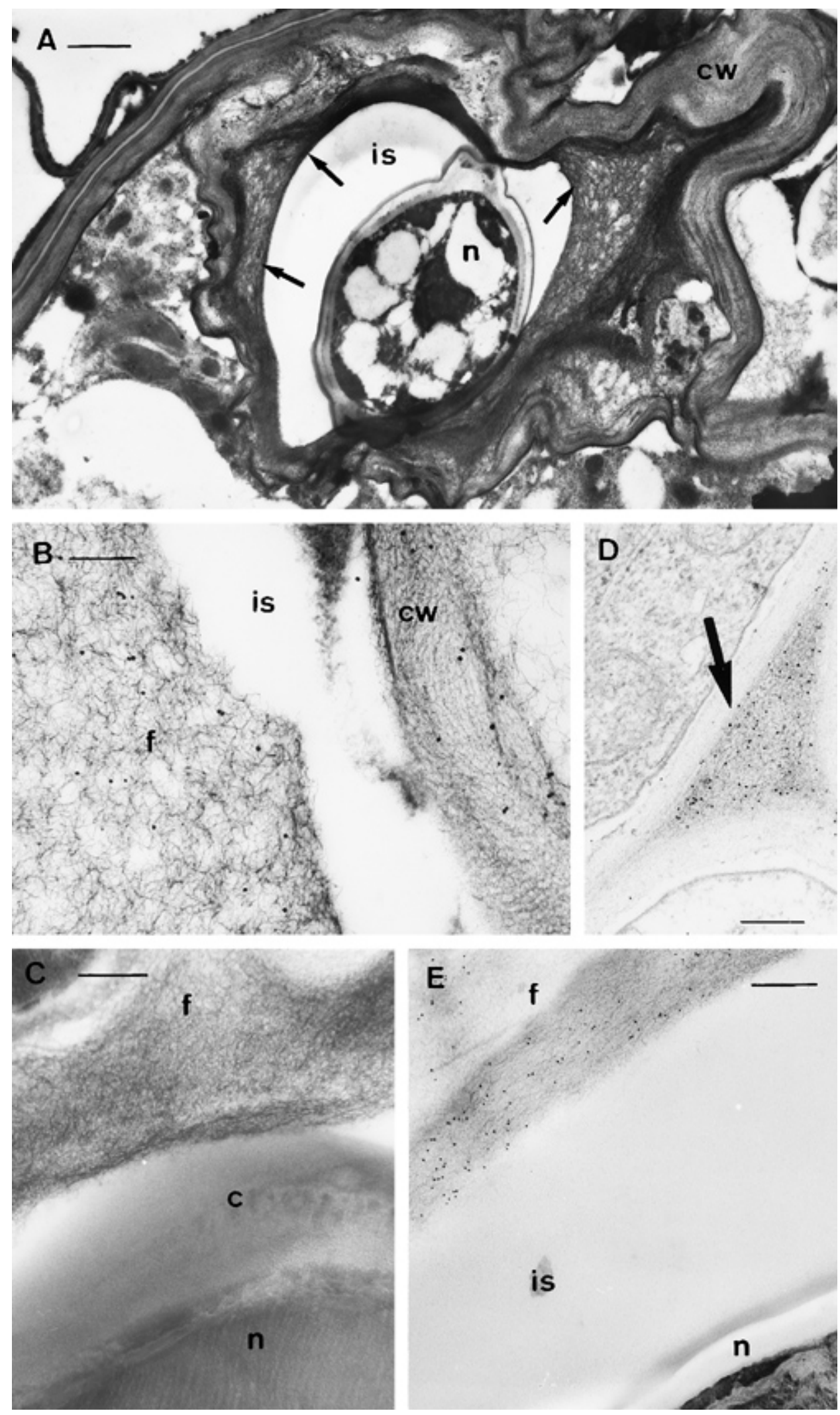

Fig. 3. A, Thin cross section within an infected susceptible root showing a nematode (n) located in the intercellular space (is) that is bordered with an electrondense fibrillar network (arrows) associated with the plant cell wall (cw). Bar $=3 \mu \mathrm{m}$. B and $\mathbf{C}$, Cytochemical localization of phenol compounds using a laccase conjugated to colloidal gold. B, Labeling is seen over the host cell wall (cw) and the fibrillar network (f) surrounding the nematode that is intercellularly located in roots of susceptible plants. $\mathbf{C}$, No gold particles are seen when the enzyme probe was previously incubated with a corresponding substrate $(\mathrm{c}=\mathrm{cuticle}$, is $=$ intercellular space, and $\mathrm{n}=$ nematode). Bars $=0.2 \mu \mathrm{m}$. D and E, Immunogold identification of pectic components using the JIM 5 monoclonal antibody. Gold particles $(10 \mathrm{~nm}$ ) are distributed over $\mathbf{D}$, the middle lamella (arrow) and $\mathbf{E}$, the fibrillar material (f) surrounding the nematode (n) located within the intercellular area (is). No labeling is observed over the nematode (n). Bars $=0.25 \mu \mathrm{m}$. 
fluorescence may result either from compounds that were not targeted by the gold probe or from an artifactual binding of Neu's reagent to nematode structures.

Several lines of evidence from other studies have demonstrated that flavonoids have various functions in plants during pathogenesis. However, their association with infection by burrowing nematodes is still poorly documented. Coumestrol, produced in bean roots infected by the lesion nematode Pratylenchus scribneri (32), was shown to be highly nematicidal to the root-knot nematode Meloidogyne incognita (23). The heavy accumulation of isoflavonoids in lucerne roots following stem colonization by Ditylenchus dipsaci has been interpreted as a defense response to a systemic signal correlated with resistance expression (9). The functional roles of these accumulating flavonoids in banana defense to $R$. similis are currently unknown. Their abnormal infiltration within plant cell walls and middle lamella may contribute to the reinforcement of cell wall structures through putative peroxidases, the activity of which was found to be higher in resistant banana cultivars than in susceptible cultivars (24). Although these phenolic compounds were not biochemically identified and tested for their nematicidal activity in vitro, there are good reasons to speculate that they may create a toxic environment for nematode ingress and multiplication. Support for this antimicrobial function in planta comes from (i) early accumulation close to the migrating channels, (ii) the presence of osmiophilic material close to the nematode in the infected tissues observed at the ultrastructural level, (iii) altered patterns in the ultrastructural organization of the nematode (38), and (iv) the few individuals and eggs recovered in resistant roots after inoculation with the parasite $(13,34,38)$.

No significant accumulation was found in either infected cultivar among the other phenolic compounds that were histochemically investigated in this study. However, variation in the detection of dopamine according to the time after infection parallels observations of Fusarium-infected banana roots with possible decompartmentalization of dopamine-linked plant defense (21). However, in the current study, no preferential localization of dopamine was evident in vascular bundles infected by $R$. similis. In parallel, biochemical experiments using bidimensional thin-layer chromatography have revealed that extracts from resistant banana roots contained two catechic tannin molecules, the content of which dramatically increased $24 \mathrm{~h}$ after infection with $R$. similis (C. Valette, unpublished data). Tannin deposition also occurred in parenchyma and endodermis cells of alfalfa roots invaded by Pratylenchus penetrans $(36,40)$, suggesting the close association of these compounds with nematode invasion. Recently, chlorogenic acid and the rice phytoalexin sakuratenin were suggested to have functional role in rice resistance to Ditylenchus angustus (30).

The current results show that phenolics in roots are associated with the defense strategy of banana to $R$. similis infection. Lignin, flavonoids, dopamine, ferulic acid, and caffeic esters are constitutive compounds that could be involved in the passive defense of the plant as chemical barriers to penetration of the parasite in roots of the partially resistant cultivar. Among mechanisms that are triggered after infection, those underlying flavonoid accumulation close to the nematode in both cultivars and in all tissues of the resistant cultivar are thought to be associated with active defense, including callose deposition and hyperplasia of vascular parenchyma cells (38). On the contrary, it is worthwhile to notice that artificial infection of banana with Helicotylenchus multicinctus does not induce any significant increase in the phenolic content of roots (24). It would now be of interest to assess whether phenolic synthesis is a key factor of resistance of banana to $R$. similis under field conditions since (i) natural infection generally occurs in association with other nematodes including Rotylenchus sp., Pratylenchus sp., Helicotylenchus sp., and Meloidogyne sp. (33), although $R$. similis is the most widely distributed $(14,33)$; and (ii) fungal and bacterial pathogens use the nematode-migrating channels as openings to colonize root tissues.

\section{ACKNOWLEDGMENTS}

We thank V. Gianinazzi-Pearson (CNRS-INRA, Dijon, France) for her helpful comments during the preparation of the manuscript. We also thank K. Roberts for providing the JIM 5 monoclonal antibody.

\section{LITERATURE CITED}

1. Andary, C., Mondolot-Cosson, L., and Daï, G. H. 1996. In situ detection of polyphenols in plant-microorganism interactions. Pages 43-54 in: Histology, Ultrastructure and Molecular Cytology of Plant-Microorganism Interactions. M. Nicole and V. Gianinazzi-Pearson, eds. Kluwer Academic Press, Dordrecht, the Netherlands.

2. Beckman, C. H. 1990. Host response to the pathogen. Pages 93-106 in: Fusarium Wilt of Banana. The American Phytopathological Society, St. Paul, MN.

3. Beckman, C. H., and Mueller, W. C. 1970. Distribution of phenols in specialized cells of banana roots. Phytopathology 60:79-82.

4. Benhamou, N., Lafontaine, P. J., and Nicole, M. 1994. Induction of systemic resistance to Fusarium crown and root rot in tomato plants by seed treatment with chitosan. Phytopathology 84:1432-1444.

5. Blake, C. D. 1966. The histological changes in banana roots caused by Radopholus similis and Helicotylenchus multicinctus. Nematologica 12: 129-137.

6. Dai, G. H., Andary, C., Mondolot-Cosson, L., and Boubals, D. 1995. Histochemical responses of leaves of in vitro plantlets of Vitis spp. to infection with Plasmopara viticola. Phytopathology 85:149-154.

7. Dai, G. H., Nicole, M., Andary, C., Martinez, C., Bresson, E., Boher, B., Daniel, J. F., and Geiger, J. P. 1996. Flavonoids accumulate in cell walls, middle lamellae and callose-rich papillae during an incompatible interaction between Xanthomonas campestris pv. malvacearum race 18 and cotton. Physiol. Mol. Plant Pathol. 49:285-306.

8. Deysson, G. 1954. Eléments d'Anatomie des Plantes Vasculaires. Sedes, Paris.

9. Edwards, R., Mizen, T., and Cook, R. 1995. Isoflavonoid conjugate accumulation in the roots of Lucerne (Medicago sativa) seedlings following infection by the stem nematode (Ditylenchus dipsaci). Nematologica 41:51-66.

10. Fallas, G., and Marban-Mendoza, N. 1994. Response of three cultivars and one hybrid of Musa to Radopholus similis. Nematropica 24:161-164.

11. Fogain, R., and Gowen, S. R. 1996. Investigations on possible mechanisms of resistance to nematodes in Musa. Euphytica 92:375-381.

12. Fogain, R., and Gowen, S. R. 1998. "Yangambi km 5" (Musa AAA, Ibota subgroup): A possible source of resistance to Radopholus similis and Pratylenchus goodeyi. Fund. Appl. Nematol. 21:75-80.

13. Gowen, S. R. 1976. Varietal responses and prospects for breeding nematode resistant banana varieties. Nematropica 6:45-49.

14. Gowen, S. R., and Quenehervé, P. 1990. Nematode parasites of bananas, plantains and abaca. Pages 431-460 in: Plant Parasitic Nematodes in Subtropical and Tropical Agriculture. M. Luć, R. Sikora, and J. Bridge, eds. Centre for Agriculture and Biosciences, London.

15. Grundler, F. M. W., Sobczak, M., and Lange, S. 1997. Defence responses of Arabidopsis thaliana during invasion and feeding site induction by the plant-parasitic nematode Heterodera glycines. Physiol. Mol. Plant Pathol. 50:419-429.

16. Jensen, W. A. 1963. Botanical Histochemistry. W. H. Freeman and Company, London.

17. Kaplan, D. T., and Davis, E. L. 1987. Mechanisms of plant incompatibility with nematodes. Pages 267-276 in: Vistas on Nematology. Academic Press, New York.

18. Knox, J. P., Linstead, P. J., King, J., Cooper, C., and Roberts, K. 1990. Pectin esterification is spatially regulated both within cell walls and between developing tissues of root apices. Planta 181:512-521.

19. Kpémoua, K., Boher, B., Nicole, M., Calatayud, P., and Geiger, J. P. 1996. Cytochemistry of defense responses in cassava infected by Xanthomonas campestris pv. manihotis. Can. J. Microbiol. 42:1131-1149.

20. Lindgren, P. B., Jakobek, J. L., and Smith, J. A. 1992. Molecular analysis of plant defense responses to plant pathogens. J. Nematol. 24:330-337.

21. Mace, M. E. 1963. Histochemical localization of phenols in healthy and diseased banana roots. Physiol. Plant. 16:915-925.

22. Mace, M. E., and Solit, E. 1966. Interactions of 3-indoleacetic acid and of 3-hydroxytyramine in Fusarium wilt of banana. Phytopathology 56: 245-247.

23. Mahajan, R., Kaur, D. J., and Bajaj, K. L. 1992. Nematicidal activity of phenolic compounds against Meloidogyne incognita. Nematol. Mediterr. 20:217-219.

24. Mateille, M. 1994. Réactions biochimiques provoquées par trois nématodes phytoparasites dans les racines de Musa acuminata (groupe AAA) variétés poyo et Gros Michel. Fund. Appl. Nematol. 17:283-290. 
25. Mondolot-Cosson, L., and Andary, C. 1994. Resistance factors of a wild species of sunflower, Helianthus resinosus, to Sclerotinia sclerotiorum. Acta Hortic. 381:642-645.

26. Neu, R. 1956. A new reagent for differentiating and determining flavones on paper chromatograms. Naturwissenschaften 43:82.

27. Nicholson, R. L., and Hammerschmidt, R. 1992. Phenolic compounds and their role in disease resistance. Annu. Rev. Phytopathol. 30:369-389.

28. Opperman, C., and Conkling, M. A. 1994. Nematode-induced plant gene expression and related control strategies. Fund. Appl. Nematol. 17:211-217.

29. Pinochet, J. 1992. Breeding bananas for resistance against lesion forming nematodes. Pages 157-169 in: Nematology from Molecule to Ecosystem. J. F. Gommers and P. W. Th. Maas, eds. European Society of Nematologists, Invergrowie, Dundee, Scotland.

30. Plowright, R. A., Grayer, R. J., Gill, J. R., Rahman, M. L., and Harborne, J. B. 1996. The induction of phenolic compounds in rice after infection by the stem nematode Ditylenchus angustus. Nematologica 42:564-578.

31. Price, N. S. 1994. Field trial evaluation of nematode susceptibility within Musa. Fund. Appl. Nematol. 17:391-396.

32. Rich, J. R., Keen, N. T., and Thomason, I. J. 1977. Associations of coumestans with the hypersensitivity of lima bean roots to Pratylenchus scribeni. Physiol. Plant Pathol. 10:105-116.
33. Sarah, J. L. 1989. Banana nematodes and their control in Africa. Nematropica 19:199-216.

34. Sarah, J. L., Blavignac, F., Sabatini, C., and Boisseau, M. 1992. Une méthode de laboratoire pour le criblage varietal des bananiers pour la resistance aux nématodes. Fruits 47:559-564.

35. Sijmons, P. C., Atkinson, H. J., and Wyss, U. 1994. Parasitic strategies of root nematodes and associated host cell responses. Annu. Rev. Phytopathol. 32:235-259.

36. Townsend, J. L., Stobbs, L., and Carter, R. 1989. Ultrastructural pathology of cells affected by Pratylenchus penetrans in alfalfa roots. J. Nematol. 21:530-539.

37. Trudgill, D. L. 1991. Resistance or tolerance of plant parasitic nematodes in plants. Annu. Rev. Phytopathol. 29:167-192.

38. Valette, C., Nicole, M., Sarah, J. L., Boisseau, M., Boher, B., Fargette, M., and Geiger, J. P. 1997. Ultrastructure and cytochemistry of interactions between banana and the nematode Radopholus similis. Fund. Appl. Nematol. 21:65-77.

39. Wehunt, E. J., Hutchinson, D. J., and Edwards, D. I. 1978. Reaction of banana cultivars to the burrowing nematode. J. Nematol. 10:368-371.

40. Zunke, U. 1990. Observations on the invasion and endoparasitic behavior of the root lesion nematode Pratylenchus penetrans. J. Nematol. 22: 309-320. 